\title{
Biología del SARS-CoV-2
}

\author{
The biology of SARS-CoV-2 \\ Dheni Aidé Fernández-Camargo,* Luis Eduardo Morales-Buenrostro* \\ * Área de Nefrología del Trasplante, Departamento de Nefrología y Metabolismo Mineral, \\ Instituto Nacional de Ciencias Médicas y Nutrición «Salvador Zubirán». Ciudad de México, México.
}

\section{RESUMEN}

Los coronavirus son una familia de virus que en años recientes han causado brotes epidémicos: el SARS en 2002, el MERS en 2012 y actualmente la pandemia de COVID-19. El SARSCoV-2 es un nuevo coronavirus que se caracteriza por ser un virus con envoltura y RNA que proviene de los murciélagos y se transmite principalmente a través de gotas respiratorias, causando una infección de vías aéreas de gravedad variable. La respuesta inmune es fundamental para el control efectivo de la infección; sin embargo, una respuesta mal regulada puede favorecer un mayor daño pulmonar y, por consiguiente, una mayor mortalidad de los pacientes. Esta revisión pretende mostrar las características del SARS-CoV-2 desde un punto de vista biológico, así como su interacción con el sistema inmune a través del cual se produce infección o enfermedad.

Palabras clave: SARS-CoV-2, COVID-19, replicación viral, inmunopatología, ECA2.

\section{ESTRUCTURA Y REPLICACIÓN VIRAL}

Los coronavirus reciben su nombre por el aspecto que le confieren sus glicoproteínas de superficie, similar a una corona solar, en la microscopia electrónica. Éstos pertenecen a la familia Coronaviridae, que se clasifica en cuatro géneros: alfacoronavirus, betacoronavirus, deltacoronavirus y gammacoronavirus. Los primeros dos tienen su origen genético en murciélagos, mientras que los últimos dos en aves. Estos virus causan enfermedades respiratorias, gastrointestinales, neurológicas y hepáticas en varias especies, incluyendo murciélagos, roedores, gatos, camellos, ganado y humanos, y son capaces de mutar con rapidez, recombinarse y transmitirse

\section{ABSTRACT}

Coronaviruses are a family of viruses that have caused epidemic outbreaks in recent years: SARS in 2002, MERS in 2012 and currently the COVID-19 pandemic. SARS-CoV-2 is a novel enveloped RNA coronavirus that originated in bats and is transmitted mainly through respiratory droplets, causing respiratory tract infection of varying severity. The immune response is critical for the effective control of the infection, however, a poorly regulated response can lead to greater lung damage and consequently higher patient mortality. This review aims to show the characteristics of SARS-CoV-2 from a biological point of view, as well as its interaction with the immune system through which infection or disease occurs.

Keywords: SARS-CoV-2, COVID-19, viral replication, immunopathology, ACE2.

de una especie a otra. ${ }^{1}$ Se han identificado siete coronavirus capaces de infectar humanos (HCoVs): HCoV-OC43, HCoV-HKU1, HCoV-229E y HCoVNL63 que causan resfriados comunes; y el SARSCoV, SARS-CoV-2 y MERS-CoV que se asocian a epidemias con una afectación respiratoria de intensidad variable. ${ }^{2}$

Es muy probable que SARS-CoV-2 se haya originado en los murciélagos, pues comparte $96 \%$ de su secuencia genética con el SARS-CoV RaTG13 encontrado en esta especie. ${ }^{3}$ Aún no se ha podido identificar un mamífero intermediario que haya servido como amplificador del virus. Se han sugerido los pangolines y víboras, pero es posible que con las mutaciones adquiridas, el virus no lo haya requerido. ${ }^{4}$ 
EI SARS-CoV-2, nombrado así debido a que su secuencia genética es similar a la del SARS-CoV en $79.6 \%,{ }^{3}$ es un betacoronavirus de 60 a $140 \mathrm{~nm}$ de diámetro, que posee una envoltura y una nucleocápside helicoidal formada por ácido ribonucleico (RNA, por sus siglas en inglés de ribonucleic acid) monocatenario positivo (+ssRNA) con 29,903 pares de bases, siendo el RNA más largo descrito en un virus. ${ }^{5-7}$ Dos tercios de su material genético (ORF1a y ORF1b) codifica para 16 proteínas no estructurales (nsps), la mayoría de ellas necesarias para el proceso de replicación y otras con funciones aún desconocidas; y del tercio restante se sintetiza RNA subgenómico que codifica proteínas estructurales (de envoltura $[E]$, membrana [M], nucleocápside [N] y espícula [S]) y proteínas accesorias entre cuyas funciones destaca la evasión de la respuesta inmune innata del huésped (Figura 1). ${ }^{8}$

\section{Proteína S}

La proteína $S$ es de fusión tipo I, altamente glucosilada, con tres heterodímeros $S_{1} / S_{2}$. Estas subunidades funcionales son generadas por la escisión que realiza una proteasa de tipo furina, ya sea la catepsina $B$ o $L$ (CatB/L) o la proteasa de serina transmembrana tipo 2 (TMPRSS2).
En $\mathrm{S}_{1}$ se encuentra el dominio de unión al receptor (RBD, por sus siglas en inglés) y es la parte más variable del genoma viral; mientras que $S_{2}$ es una subunidad altamente conservada, que media la fusión con la membrana celular y hace posible su ingreso a la célula. Debido a que realiza una función indispensable, la proteína $S$ es el blanco principal de los anticuerpos neutralizantes. ${ }^{9,10}$

Al comparar las características de SARS-CoV-2 y SARS-CoV se vio que comparten únicamente el $40 \%$ de los aminoácidos del RBD y que la proteína $S$ de SARS-CoV-2 tiene mayor afinidad por su receptor. ${ }^{10}$ La principal diferencia entre ambas proteínas es una inserción de 12 nucleótidos entre $S_{1}$ y $S_{2}$, que forman un motivo polibásico reconocido por furina. Se han encontrado mutaciones similares en virus altamente patogénicos como el de la influenza, por lo que esto, junto con la alta afinidad a su receptor, podrían ser la causa de la transmisión tan eficiente del SARS-CoV-2. ${ }^{9-11}$

\section{Enzima convertidora de angiotensina 2 (ECA2)}

La enzima convertidora de angiotensina (ECA) 2 (ECA2) y su proteína homóloga ECA, participan en la regulación de la presión arterial al controlar el sistema renina-angiotensina-aldosterona (RAAS). ECA con-

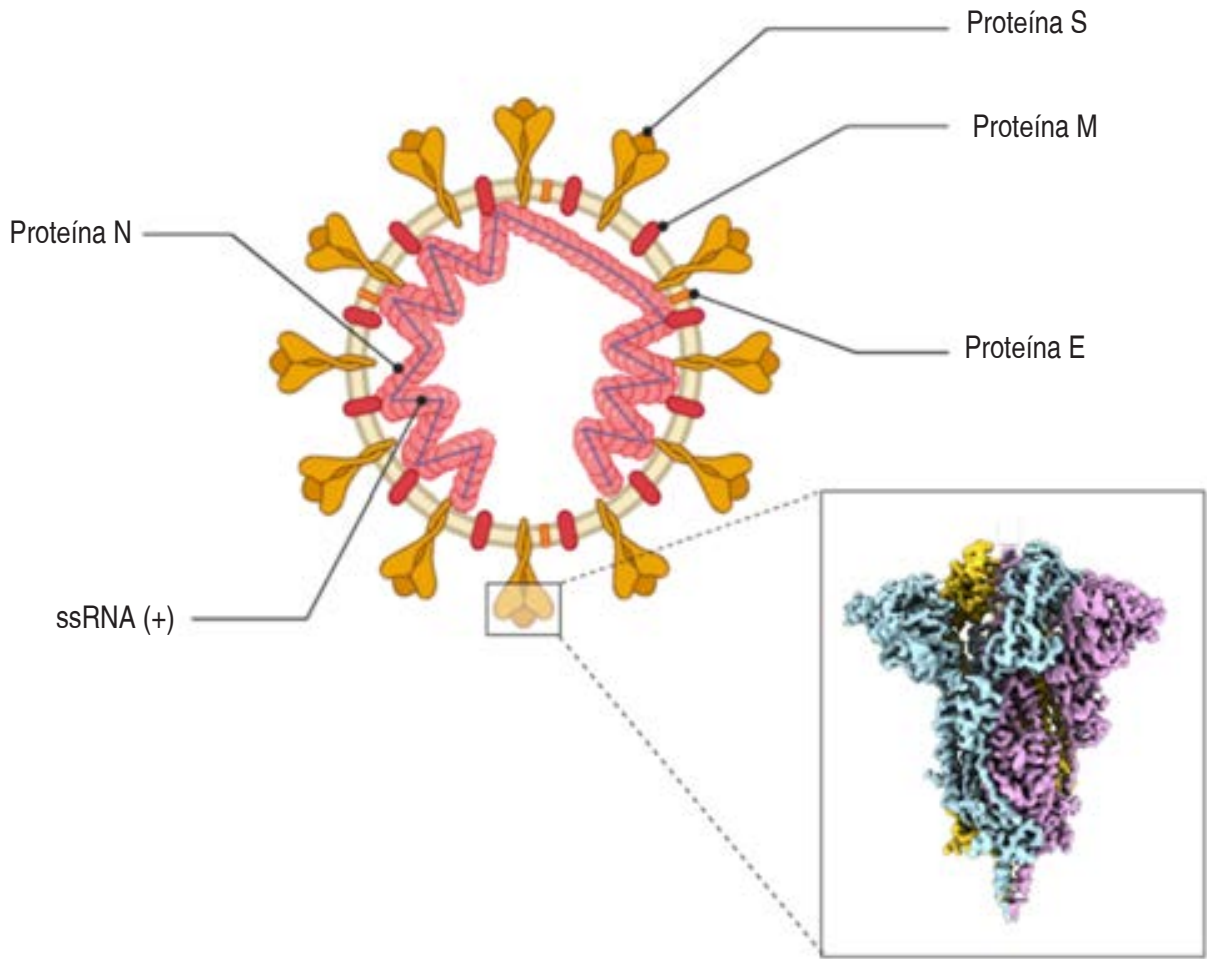

Trímero de proteína S
Figura 1:

Estructura del virus SARS-CoV-2. 
vierte la angiotensina I (Ang I) en angiotensina II (Ang II) y a su vez, ECA2 convierte Ang II en angiotensina 1-7 (Ang 1-7), que es un péptido antiinflamatorio. La Ang II al unirse a su receptor, el receptor de angiotensina II tipo 1a (AT1R), produce vasoconstricción y retención de sodio, pero también puede causar edema, inflamación y fibrosis pulmonar. ${ }^{8,12}$

La ECA2 es una proteína de membrana que se encuentra presente de manera abundante en las células alveolares del sistema respiratorio, especialmente en los neumocitos tipo II, y en humanos también se encuentra en el intestino delgado, endotelio, corazón, riñones, entre otros tejidos. ${ }^{13}$

EI SARS-CoV y el SARS-CoV-2 utilizan esta enzima como receptor para poder infectar a las células que la expresan en la superficie. ${ }^{3,5}$ Una vez que la proteína $S$ del virus se une a ECA2, ambas se internalizan, causando una disminución de la expresión de ECA2. ${ }^{14}$

A pesar de esto, se ha reportado que el SARS-CoV puede ingresar a las células que no expresan o expresan con baja frecuencia esta enzima, como los macrófagos alveolares y, por el contrario, no hay evidencia de infección de células endoteliales que sí expresan ECA2, por lo que probablemente posea otros mecanismos de infección no descritos, como el uso de correceptores. ${ }^{15}$ Uno de estos mecanismos parece estar relacionado con el tipo de proteasa que escinde a la proteína $S$ y permite que el virus se internalice. En un estudio in vitro se demostró que la coexpresión de ECA2 y de TMPRSS2, no así de CatB/L, es necesaria para la entrada del SARSCoV-2 a las células pulmonares, y esto es bloqueado parcialmente mediante el uso de inhibidores de proteasa (como el mesilato de Camostat) con los que ya se están haciendo ensayos clínicos (ClinicalTrials.gov, NCT04321096). ${ }^{16}$ La TMPRSS2 es una proteína de membrana que se expresa en las células epiteliales de los tractos respiratorio y digestivo, así como en el riñón, especialmente en los podocitos y el túbulo proximal. ${ }^{17}$

Varios estudios han investigado la expresión de ECA2 en diferentes etnias, ya que esto podría estar implicado en la susceptibilidad o respuesta al SARSCoV-2. En uno de ellos se vio que la población de Asia del Este presentaba una mayor frecuencia alélica en el gen de ECA2 comparado con otras poblaciones, lo que se asocia con una mayor expresión de esta enzima en los tejidos. ${ }^{18}$

\section{Replicación viral}

Durante la infección, el coronavirus entra a los neumocitos tipo II y otras células mediante la unión de la proteína S con el receptor ECA2. La proteína S es escindida por una proteasa (TMPRSS2 o CatB/L) en $\mathrm{S}_{1} /$ $S_{2}$ y $S_{2}$, que separa las dos subunidades y produce un cambio de conformación para activar su estado de fusión. ${ }^{9,13}$ Una vez dentro de la célula, el genoma viral se libera al citoplasma y los ribosomas del huésped inician la traducción del gen de la replicasa, que consiste en dos ORF (open reading frame) que codifican para dos poliproteínas. Las poliproteínas (pp1a y pp1ab) son escindidas por dos proteasas virales (PLpro y 3CLpro) en 16 proteínas no estructurales (nsp1-nsp16) que conforman el complejo viral de replicación-transcripción (RTC). Los nsps forman vesículas de doble membrana a partir del retículo endoplásmico rugoso (RER), en donde tiene lugar la replicación viral. Dentro de estas vesículas, una RNA polimerasa dependiente de RNA genera moldes de RNA de cadena negativa que utiliza para replicar nuevos genomas y transcribe siete a nueve RNA subgenómicos, a partir de los cuales se sintetizan las proteínas estructurales. Una vez sintetizadas, las proteínas $E, M$ y $S$ se asocian al retículo endoplásmico y $\mathrm{N}$ forma la nucleocápside al unirse al RNA viral. Los viriones se ensamblan en el compartimiento intermedio retículo endoplásmicoGolgi (ERGIC) de donde salen en vesículas que migran hacia la membrana y son liberados de la célula infectada mediante exocitosis (Figura 2).-9

A diferencia de otros virus RNA, los coronavirus tienen una exonucleasa (ExoN), encargada de mantener la fidelidad de la transcripción de su genoma y evitar la

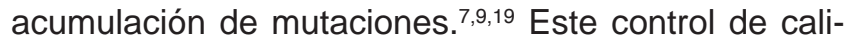
dad de la transcripción le hace resistente a la ribavirina y posiblemente a otros antivirales.

\section{INCUBACIÓN, TRANSMISIÓN Y SUPERFICIES}

\section{Incubación}

El periodo de incubación en la mayoría de los casos es de tres a siete días, pudiendo llegar hasta los 14 días. Un estudio realizado en China con 88 casos confirmados reportó un periodo de incubación promedio de 6.4 días ( IC95\%, 5.6-7.7 días) con un rango de 2.1 a 11.1 días:20 mientras que en otro estudio con 181 casos confirmados se estimó en 5.1 días ( IC95\%, 4.5 a 5.8 días). ${ }^{21}$ Estos datos son muy similares a los descritos en otros coronavirus como los causantes del SARS y del MERS, cuyo periodo de incubación es de aproximadamente cinco días y el $95 \%$ de los pacientes desarrolla síntomas dentro de los 13 días posteriores a la exposición. ${ }^{8}$ 


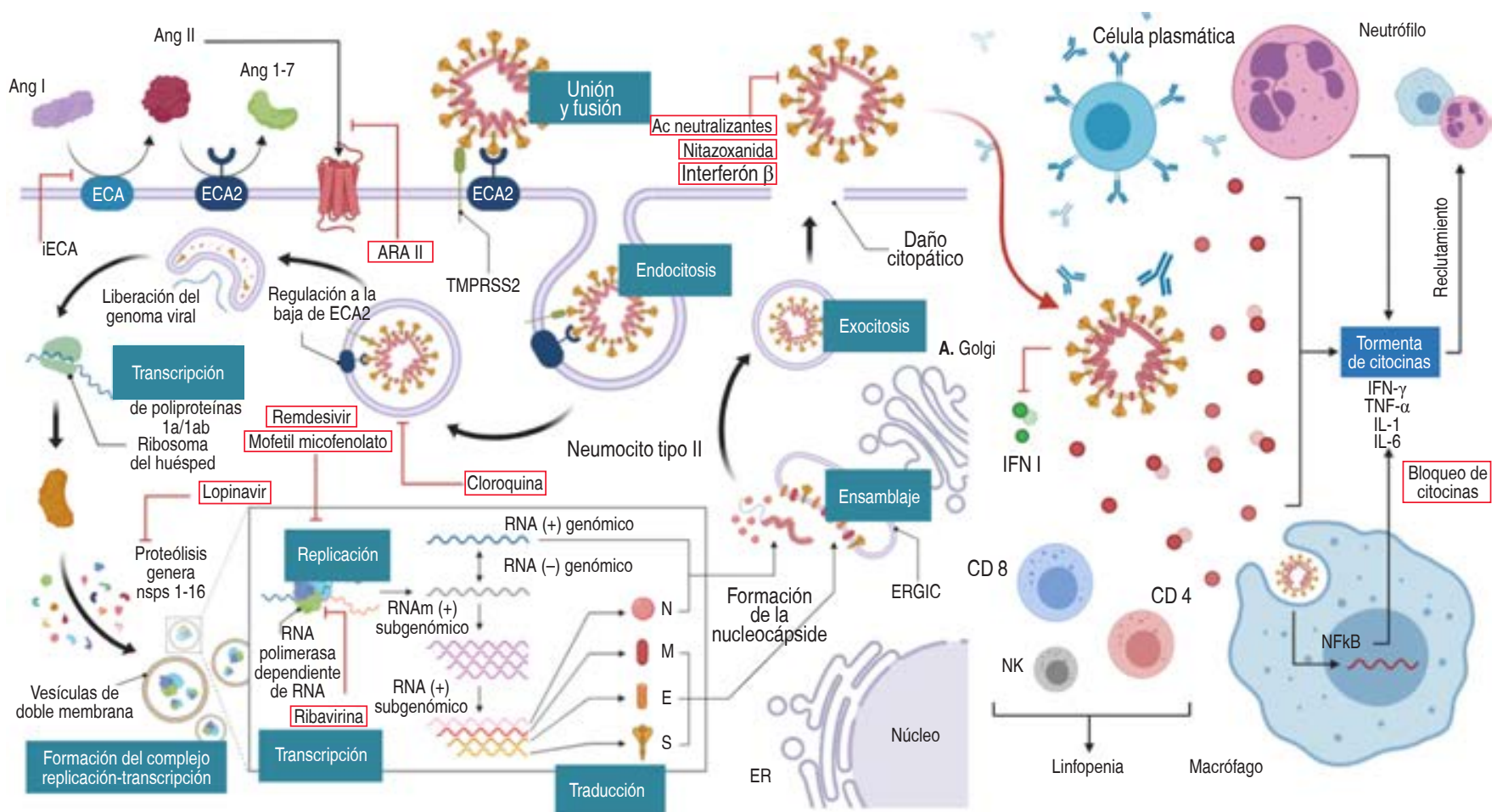

Figura 2: Mecanismo de invasión, replicación y patogenia viral, así como sitios de acción de diferentes fármacos.

Los síntomas se presentan de tres a seis días después de la exposición. Se estima que menos del $2.5 \%$ de las personas infectadas manifestarán síntomas en los siguientes 2.2 días de la infección, pero a los 11.5 días ya el $97.5 \%$ presentarán síntomas y después de 14 días es muy poco probable que desarrollen síntomas. Por esta razón, muchos organismos internacionales, como la Organización Mundial de la Salud, han estipulado que el periodo de cuarentena debe durar dos semanas. ${ }^{21}$

\section{Transmisión}

El virus se transmite de humano a humano principalmente a través de gotas respiratorias, aunque también se ha identificado en heces. ${ }^{22,23}$ La transmisión por aerosoles puede ocurrir si se está expuesto a altas concentraciones de éstos por tiempo prolongado en espacios cerrados; y aunque la transmisión por contacto con superficies contaminadas es posible, no parece ser la vía principal de transmisión. En todo caso, se requiere que las superficies contaminadas (manos, guantes $u$ otros objetos) alcancen la mucosa oral, nasal, e incluso las conjuntivas, donde existe ECA2. Actualmente, no hay evidencia de transmisión vertical. ${ }^{24}$ Se ha visto que su propagación se limita principalmen- te a miembros de la familia y personal de salud, lo que sugiere que es necesario que haya contacto cercano entre individuos. ${ }^{25}$

A pesar de que la presentación de síntomas se relaciona con la transmisibilidad de la infección, se ha reportado que personas asintomáticas también pueden transmitir el virus hasta 12 horas antes de presentar las manifestaciones clínicas, por lo que el periodo de latencia (tiempo comprendido de la infección al momento en el que se puede transmitir el patógeno) podría ser menor que el periodo de incubación (tiempo desde la infección a la aparición de síntomas), y esto también podría explicar su alta transmisibilidad. ${ }^{21,26,27}$

\section{Viabilidad del virus en superficies}

El SARS-CoV-2 permanece viable en aerosoles $(<5$ $\mu \mathrm{m})$ al menos durante tres horas. El plástico y el acero inoxidable son las superficies en donde el virus es más estable, pudiendo permanecer hasta 72 horas, aunque los títulos virales se reducen de manera importante. En cobre, la viabilidad del virus fue de cuatro horas, mientras que sobre cartón fue de 24 horas. ${ }^{28}$

Al igual que otros coronavirus, el SARS-CoV-2 es sensible a la radiación ultravioleta y al calor, y se pue- 
de inactivar con solventes lipídicos como el etanol, el éter y el cloro, aunque la clorhexidina parece no ser efectiva. ${ }^{25}$

\section{FISIOPATOLOGÍA Y RESPUESTA INMUNE}

Hasta el momento, la información que se tiene sobre la patogenia de este nuevo virus es escasa. Se sabe que la secuencia del SARS-CoV-2 es similar en el $79.6 \%$ al SARS-CoV, por lo que se cree que los mecanismos fisiopatogénicos podrían ser muy parecidos. ${ }^{15}$

Generalmente, los coronavirus causan infecciones leves de vías respiratorias altas, pero cuando infecta las vías respiratorias inferiores causan enfermedades más graves, como en los brotes de SARS y MERS. ${ }^{7}$

Durante la infección, se inicia una respuesta inmune exacerbada contra el virus, que es responsable de las diferentes manifestaciones clínicas y del daño del epitelio respiratorio. Los factores clave para generar esta respuesta inmune son la rápida replicación viral, su capacidad para reclutar células del sistema inmune, especialmente macrófagos y neutrófilos, la liberación de mediadores de inflamación, así como la disminución del número y la respuesta de los linfocitos T. 15,19,29

Ingreso a la célula: proteína S y ECA2

Al ingresar a las vías respiratorias, el virus causa disminución del movimiento ciliar y daño celular como consecuencia de su replicación. Aunado a este daño, la disminución en la expresión de ECA2 causa una pérdida de la regulación del RAAS, lo que provoca un incremento en la concentración y actividad de Ang II a través de AT1R, que produce vasoconstricción, aumento en la permeabilidad vascular, infiltración por neutrófilos y daño pulmonar, como se ha demostrado en modelos animales. ${ }^{8,13,14,30}$ Sin embargo, se ha observado que a pesar de que otro coronavirus (CoVNL63) también usa ECA2 como receptor, la infección por esta cepa no se asocia con daño pulmonar grave. ${ }^{31}$

Una de las características de los pacientes con enfermedad por coronavirus 2019 (COVID-19) grave, es la presencia de comorbilidades, especialmente hipertensión arterial, diabetes mellitus y enfermedades cardiacas. ${ }^{32}$ Estas tres patologías tienen en común el uso de fármacos antagonistas del RAAS, como los inhibidores de la enzima convertidora de angiotensina (iECA) y los antagonistas de receptores de angiotensina II (ARA), los cuales han demostrado, aunque no de manera contundente, que aumentan la expresión de ECA2. Por ello, se llegó a plantear la hipótesis (ya refutada) de que el aumento de ECA2 facilitaría la infección por SARS-CoV-2 y aumentaría el riesgo de enfermedad grave y muerte, e incluso se ha llegado a sugerir la suspensión de estos fármacos en pacientes con COVID-19 y el cambio a antagonistas de canales de calcio. ${ }^{33,34}$

Por otra parte, se propone que los fármacos antagonistas de AT1R, en lugar de aumentar el riesgo de infección, podrían tener un efecto protector mediante la inducción de la expresión de ECA2 y el bloqueo de la actividad de AT1R y, por consiguiente, del daño pulmonar mediado por Ang II. Esto coincide con datos de pacientes con COVID-19, quienes presentaban niveles elevados de Ang II que correlacionaban con la carga viral y gravedad de la enfermedad. ${ }^{35,36}$ En un estudio con modelos murinos de neumonía por SARS e influenza A se comprobó que el uso de losartán y ECA2 recombinante era protector para daño pulmonar agudo; ${ }^{30}$ sin embargo, cuando se administró ECA2 recombinante a pacientes con síndrome de insuficiencia respiratoria aguda en un estudio de fase 2 , no hubo mejoría en los parámetros fisiológicos ni clínicos de los pacientes comparado con placebo. ${ }^{37}$

Ambas hipótesis se basan en el aumento de la expresión de ECA2 mediada por antagonistas del RAAS. No obstante, los estudios que se han hecho muestran resultados contradictorios. En algunos se ha demostrado un aumento en la expresión de ECA2 en corazón y riñón de ratones tratados con losartán y olmesartán, mientras que en otros no se ha visto que alteren su expresión. ${ }^{38-40}$ En humanos se ha observado que únicamente el olmesartán y el captopril como monoterapia aumentan los niveles urinarios de ECA2 y de Ang 1-7 en el plasma, respectivamente. . $^{41,42}$

El Colegio Americano de Cardiología (ACC) y otras sociedades han rechazado la sustitución de los iECA o ARA con calcioantagonistas y tampoco apoyan la administración de estos medicamentos como tratamiento específico de COVID-19, debido a que actualmente no hay evidencia experimental ni clínica de los efectos de los iECA ni de los ARA sobre la expresión de ECA2 específicamente en el pulmón y tampoco de su efecto en la entrada del virus, además de que la suspensión o modificación del tratamiento podría causar descompensación en los pacientes y los pondría en riesgo innecesario. ${ }^{36,43}$

El riñón también coexpresa ECA2 y TMPRSS2, especialmente en el túbulo proximal y en los podocitos, en una proporción similar a otros órganos, como los pulmones y el intestino delgado. Esto sugiere que el riñón puede ser un órgano blanco importante de la in- 
fección por SARS-CoV-2. ${ }^{17}$ Se ha observado que del 0.9 al 29\% de los pacientes con COVID-19 presentan lesión renal aguda y el $43 \%$ proteinuria; sin embargo, se desconocen los mecanismos fisiopatológicos mediante los cuales el SARS-CoV-2 afecta al riñón..44,45 Uno de los posibles mecanismos que ha sido sugerido es la citotoxicidad directa del virus, ya que se han encontrado partículas virales en las células del túbulo proximal y los podocitos, además de necrosis tubular aguda, glomeruloesclerosis focal y segmentaria colapsante, daño endotelial, trombos de fibrina y congestión de los capilares peritubulares y glomerulares como resultado de un estado procoagulable sistémico y cambios compatibles con nefropatía diabética o hipertensiva preexistente. ${ }^{46}$

\section{Papel de la inmunidad innata}

Después de la entrada del virus a las células, el sistema inmune innato monta una respuesta inmediata e inespecífica en contra del virión al reconocer el RNA viral. El material genético del SARS-CoV-2, al igual que el de otros virus, es un patrón molecular asociado con patógeno, el cual es reconocido por los receptores de reconocimiento de patrones como TLR-3, TRL-7, TLR-8, RIG-I y MDA-5 que se encuentran en las células presentadoras de antígenos, especialmente en las células dendríticas. Esto desencadena cascadas de señalización que llevan a la producción de interferones (IFN) de tipo I (IFN- $\boldsymbol{\alpha}$ e IFN- $\boldsymbol{\beta}$ ) y a la activación del factor de transcripción NFKB (por sus siglas en inglés de: nuclear factor kappa-light-chain-enhancer of activated $B$ cells). Los IFN de tipo I a través de la vía de señalización de STAT inician la transcripción de proteínas antivirales codificadas en genes estimulados por IFN; mientras que NF $\kappa B$ induce la transcripción de citocinas proinflamatorias. ${ }^{8}$ Éstas, junto con otros mediadores de inflamación liberados como consecuencia del daño citopático, reclutan macrófagos y neutrófilos, lo que resulta en una hiperproducción de citocinas proinflamatorias y especies reactivas de oxígeno, similar a la «tormenta de citocinas» descrita en SARS y MERS, que favorecen la vasodilatación, fuga vascular y el edema alveolar, además de la acumulación de detritos celulares dentro de los alvéolos y la aparición de membranas hialinas, que en conjunto causan hipoxia. ${ }^{8,15}$ La interleucina (IL)-1, IL-6 y el factor de necrosis tumoral alfa (TNF- $\alpha$ ), al ser pirógenos endógenos, actúan sobre el hipotálamo para producir fiebre.

No existe evidencia directa del papel fisiopatológico de los mediadores de inflamación en COVID-19, pero sí se ha visto que el grado de respuesta inflamatoria se asocia con la gravedad de la enfermedad. En un estudio se reportó que pacientes infectados con SARS-CoV-2 presentaban un incremento en los niveles de IL-1 $\beta$, IFN $\gamma$, CXCL10 o proteína inducida por interferón 10 (IP-10) y la proteína quimioatrayente de monocitos 1 (MCP-1), que probablemente llevan a la activación de la respuesta Th1, y que aquellos pacientes que requerían ser ingresados a una Unidad de Terapia Intensiva tenían concentraciones más altas de factor estimulante de colonias de granulocitos, IP-10, MCP-1, proteína inflamatoria de macrófagos 1-alfa y TNF $\alpha .{ }^{6}$ En SARS se observó algo similar: los pacientes con niveles elevados de las citocinas proinflamatorias (IFN tipo I) y genes estimulados por IFN presentaban mayor mortalidad. ${ }^{19}$ Esta respuesta inmune excesiva o mal regulada podría ser el punto central de la fisiopatología en COVID-19, y la causa que los pacientes presenten síndrome de insuficiencia respiratoria aguda, choque séptico, falla orgánica múltiple y eventualmente la muerte. ${ }^{15,47}$

\section{Papel de la inmunidad adaptativa}

La respuesta celular en pacientes con COVID-19 está mediada principalmente por linfocitos T CD8+, que son los responsables de la destrucción directa de las células infectadas. Sin embargo, la gran cantidad de IL-6 producida durante la tormenta de citocinas podría bloquear esta respuesta, al inhibir la secreción de IFN $\gamma$ y aumentar la expresión de proteína de muerte celular programada 1 conocida como PD-1, como se ha descrito en otras infecciones virales. ${ }^{48,49}$ Por otro lado, la otra subpoblación de linfocitos T, los CD4+, desempeñan también un papel importante en el control del virus al incidir en la generación de la respuesta humoral, ya que la respuesta celular intensa se relaciona directamente con una mayor producción de anticuerpos neutralizantes contra el virus. ${ }^{48,50}$ En pacientes con SARS se asoció la gravedad de la enfermedad con la falta de transición de una respuesta inmune innata a una adaptativa. ${ }^{8}$

Se ha reportado que hasta el $82 \%$ de los pacientes con COVID-19 cursan con linfopenia, siendo la población celular más afectada la de los linfocitos $\mathrm{T}$, específicamente los CD4+, mientras que la cantidad de CD8+, células natural killer, B y T reguladoras disminuyen en menor medida. Además de su reducción, también se observó una hiperactivación celular y con ello, un aumento en la producción de citocinas proinflamatorias y gránulos citotóxicos. Esta alteración en 
la regulación de la respuesta inmune es más pronunciada en pacientes que desarrollan las formas graves de la enfermedad. ${ }^{51}$ También se ha observado que, a diferencia del SARS, los pacientes con COVID-19 presentan un aumento en la producción de IL-4 e IL-10 (respuesta Th2) que se asocia con una disminución de la inflamación. ${ }^{6}$

Además de la presencia de comorbilidades, la inmunosenescencia parece ser un factor clave que aumenta la mortalidad en estos pacientes. En adultos mayores la población de linfocitos $T$ naïve está disminuida y la de linfocitos de memoria aumenta, por lo que su sistema inmune se encuentra más apto para responder ante la presencia de patógenos con los que ha estado en contacto previamente que con microorganismos con quienes interactúa por primera vez, como el nuevo coronavirus, SARS-CoV-2; contrario a lo que ocurre en los niños, que suelen tener una mayor cantidad de linfocitos T naïve. Esto explicaría la presentación clínica más grave y con tasas de mortalidad más altas en los adultos mayores comparado con la población infantil. ${ }^{49}$

La respuesta humoral, mediante la producción de anticuerpos neutralizantes, tiene un papel importante en el control de la infección y también en la prevención de una reinfección. Éstos reducen la infectividad del virus al unirse a algunas proteínas virales de superficie y prevenir así la unión del virus con su receptor y por consiguiente su internalización. También promueven la lisis del virus mediante opsonización o activación del complemento. ${ }^{50}$

Se han realizado algunos estudios en los que se analiza la seroconversión en pacientes con COVID-19. En uno de ellos se incluyeron cinco pacientes y se observó que 20 días después del inicio de la enfermedad, en todos se detectaron niveles de IgG específica contra el virus, y también tres de ellos eran positivos para IgM, lo que indicaba que los pacientes aún presentaban infección aguda. ${ }^{3}$ En otro estudio con 173 pacientes, menos del $40 \%$ presentaba anticuerpos siete días después del inicio de los síntomas y a partir del día 15 , el $94.3 \%$ presentaban IgM y $79.8 \%$ IgG. Esto permitió calcular el tiempo promedio para la seroconversión en 12 días para IgM y 14 días para IgG. ${ }^{52}$ Estos datos concuerdan con los reportados en pacientes con SARS, en los que la formación de anticuerpos se observaba a partir del día cuatro y la mayoría había seroconvertido a los 14 días. ${ }^{15}$ Sin embargo, a pesar de montar una respuesta con anticuerpos neutralizantes, ésta no es sostenida: alcanza un pico a los cuatro meses y a los dos años empiezan a disminuir. ${ }^{53,54}$
A pesar de que los anticuerpos neutralizantes son importantes para el control de la infección por SARS$\mathrm{CoV}$, en particular la presencia de IgG anti-S, se han relacionado con daño pulmonar agudo durante las etapas iniciales de la infección por SARS-CoV al promover la acumulación de macrófagos M1 y la producción de IL-8, MCP-1 en este órgano, además de bloquear la producción de TGF $\boldsymbol{\beta}$ y la actividad de macrófagos M2. ${ }^{55}$ De igual forma, se ha visto que la aparición de anticuerpos neutralizantes coincide con el desarrollo de síndrome de insuficiencia respiratoria aguda en pacientes con SARS, y que una seroconversión más temprana con títulos más altos se asociaba a mayor mortalidad. ${ }^{56,57}$ Esta respuesta podría ser causada por la amplificación dependiente de anticuerpos, donde la unión de complejos inmunes virus-IgG-anti-S con receptores $\mathrm{Fc} \gamma \mathrm{R}$ u otros receptores aumenta la entrada del virus a las células y la persistencia de la replicación viral. ${ }^{58}$

Tras la recuperación de la infección, se asume que las personas son inmunes a una reinfección a corto plazo, como sucede con cepas estacionales de coronavirus, en donde es muy poco probable que se vuelvan a infectar con la misma cepa en esa temporada o la siguiente. ${ }^{26}$

\section{Evasión de la respuesta inmune}

Una de las características de los coronavirus es su capacidad de evadir la respuesta inmune, principalmente mediante la inhibición o retraso en la síntesis de IFN tipo I a través de nsp1 y nsp3, lo que permite una mayor replicación viral y daño pulmonar, así como la inducción de apoptosis de células $\mathrm{T}$, generando linfopenia y, por lo tanto, una respuesta inmune mal controlada. Además de esto, evitan que su RNA sea reconocido al replicarse dentro de vesículas de doble membrana que no tienen receptores de reconocimiento de patrones. . $^{8,19,29,47} \mathrm{El}$ hecho de que pacientes asintomáticos con COVID-19 transmitan el virus puede ser un indicador de una respuesta retardada del sistema inmune innato para el control viral. ${ }^{15}$

En conclusión, el SARS-CoV-2 es un virus emergente que comparte muchas de sus características con otros coronavirus, como los responsables de las pandemias del SARS y del MERS. Gran parte de lo que se sabe actualmente sobre su fisiopatología está basada en conocimientos previos sobre el SARS. Ambos virus usan la enzima ECA2 como receptor; sin embargo, se ha demostrado que el SARS-CoV-2 tiene una mayor afinidad por ésta, lo que podría ex- 
plicar su alta contagiosidad, y contrario a lo que se creía inicialmente, los antihipertensivos inhibidores de la ECA y ARA2 podrían conferir un mejor pronóstico a los pacientes. La respuesta inmune que se genera tras la infección es un factor clave en la enfermedad, ya que puede derivar en un control eficiente del virus o en la generación de una respuesta mal regulada en la que hay un exceso en la producción de citocinas proinflamatorias asociado con una respuesta celular y humoral subóptima, lo que se relaciona con mayor daño pulmonar y por consiguiente con mayor mortalidad de los pacientes. Aún falta mucho por conocer sobre la interacción entre este nuevo virus y el sistema inmune; sin embargo, en todo el mundo se están realizando innumerables proyectos de investigación que han dado como resultado una cantidad importante de información sobre este nuevo virus en muy poco tiempo, por lo que es plausible la idea de que en poco tiempo contemos con nuevas terapias antivirales y vacunas que permitan el control de esta pandemia, así como de brotes futuros.

\section{REFERENCIAS}

1. Chan JFW, Yuan S, Kok KH, To KKW, Chu H, Yang J et al. A familial cluster of pneumonia associated with the 2019 novel coronavirus indicating person-to-person transmission: a study of a family cluster. Lancet [Internet]. 2020; 395 (10223): 514-523. Available in: http://dx.doi.org/10.1016/S0140-6736(20)30154-9

2. Chen $Y$, Liu Q, Guo D. Emerging coronaviruses: Genome structure, replication, and pathogenesis. J Med Virol. 2020; 92 (4): 418-423.

3. Zhou P, Yang XL, Wang XG, Hu B, Zhang L, Zhang W et al. A pneumonia outbreak associated with a new coronavirus of probable bat origin. Nature [Internet]. 2020; 579 (7798): 270273. Available in: http://dx.doi.org/10.1038/s41586-020-2012-7.

4. Wang $Y$, Wang $Y$, Chen $Y$, Qin $Q$. Unique epidemiological and clinical features of the emerging 2019 novel coronavirus pneumonia (COVID-19) implicate special control measures. J Med Virol [Internet]. 2020. Available in: http://www.ncbi.nlm.nih. gov/pubmed/32134116

5. Wu F, Zhao S, Yu B, Chen YM, Wang W, Song ZG et al. A new coronavirus associated with human respiratory disease in China. Nature. 2020; 579 (7798): 265-269.

6. Huang C, Wang Y, Li X, Ren L, Zhao J, Hu Y et al. Clinical features of patients infected with 2019 novel coronavirus in Wuhan, China. Lancet. 2020; 395 (10223): 497-506.

7. Perlman S, Mcintosh K. 155-Coronaviruses, Including severe acute respiratory syndrome (SARS) and middle east respiratory syndrome (MERS) [Internet]. 9th ed. Mandell, Douglas, and Bennett's Principles and Practice of Infectious Diseases. Elsevier Inc.; 2020. pp. 2072-2080.e3. Available in: https://doi. org/10.1016/B978-0-323-48255-4.00155-7.

8. De Wit E, Van Doremalen N, Falzarano D, Munster VJ. SARS and MERS: recent insights into emerging coronaviruses. Nat Rev Microbiol. 2016; 14 (8): 523-534.

9. Walls AC, Park YJ, Tortorici MA, Wall A, McGuire AT, Veesler D. Structure, function, and antigenicity of the SARS-CoV-2 spike glycoprotein. Cell [Internet]. 2020; 1-12. Available in: http://www. ncbi.nlm.nih.gov/pubmed/32155444

10. Wrapp D, Wang N, Corbett KS, Goldsmith JA, Hsieh CL, Abiona $O$ et al. Cryo-EM structure of the 2019-nCoV spike in the prefusion conformation. Science. 2020; 367 (6483): 1260-1263.

11. Coutard B, Valle C, de Lamballerie X, Canard B, Seidah NG, Decroly $E$. The spike glycoprotein of the new coronavirus 2019-nCoV contains a furin-like cleavage site absent in CoV of the same clade. Antiviral Res [Internet]. 2020; 176: 104742. Available in: https://doi.org/10.1016/j.antiviral.2020.104742

12. Hendrickson CM, Matthay MA. Viral pathogens and acute lung injury: Investigations inspired by the SARS epidemic and the 2009 H1N1 influenza pandemic. Semin Respir Crit Care Med. 2013; 34 (4): 475-486.

13. Chen J, Subbarao K. The Immunobiology of SARS. Annu Rev Immunol. 2007; 25 (1): 443-472.

14. Kuba K, Imai Y, Rao S, Gao H, Guo F, Guan B et al. A crucial role of angiotensin converting enzyme 2 (ACE2) in SARS coronavirusinduced lung injury. Nat Med. 2005; 11 (8): 875-879.

15. Prompetchara E, Ketloy C, Palaga T. Immune responses in COVID-19 and potential vaccines: Lessons learned from SARS and MERS epidemic. Asian Pacific $J$ allergy Immunol [Internet]. 2020. Available in: http://www.ncbi.nlm.nih.gov/ pubmed/32105090

16. Hoffmann M, Kleine-Weber H, Schroeder S, Krüger N, Herrler T, Erichsen S et al. SARS-CoV-2 Cell Entry Depends on ACE2 and TMPRSS2 and Is Blocked by a Clinically Proven Protease Inhibitor. Cell. 2020; 181 (2): 271-280.e8.

17. Pan XW, Xu D, Zhang $H$, Zhou W, Wang LH, Cui XG. Identification of a potential mechanism of acute kidney injury during the COVID-19 outbreak: a study based on single-cell transcriptome analysis. Intensive Care Med. 2020; 1-3. doi: 10.1007/s00134-020-06026-1.

18. Cao Y, Li L, Feng Z, Wan S, Huang P, Sun X et al. Comparative genetic analysis of the novel coronavirus (2019-nCoV/SARSCoV-2) receptor ACE2 in different populations. Cell Discov [Internet]. 2020; 6 (1): 4-7. Available in: http://dx.doi.org/10.1038/ s41421-020-0147-1

19. Perlman S, Netland J. Coronaviruses post-SARS: Update on replication and pathogenesis. Nat Rev Microbiol. 2009; 7 (6): 439-450.

20. Backer JA, Klinkenberg D, Wallinga J. Incubation period of 2019 novel coronavirus (2019-nCoV) infections among travellers from Wuhan, China, 20-28 January 2020. Euro Surveill. 2020; 25 (5): 1-6.

21. Lauer SA, Grantz KH, Bi Q, Jones FK, Zheng Q, Meredith $\mathrm{HR}$ et al. The incubation period of coronavirus disease 2019 (COVID-19) from publicly reported confirmed cases: estimation and application. Ann Intern Med [Internet]. 2020. Available in: http://www.ncbi.nlm.nih.gov/pubmed/32150748

22. Jiang X, Rayner S, Luo MH. Does SARS-CoV-2 has a longer incubation period than SARS and MERS? J Med Virol. 2020; 92 (5): 476-478.

23. Ong SWX, Tan YK, Chia PY, Lee TH, Ng OT, Wong MSY et al. Air, surface environmental, and personal protective equipment contamination by severe acute respiratory syndrome coronavirus 2 (SARS-CoV-2) from a symptomatic patient. JAMA [Internet]. 2020; 323 (16): 1610-1612. Available in: http://www. ncbi.nlm.nih.gov/pubmed/32129805

24. Chen H, Guo J, Wang C, Luo F, Yu X, Zhang W et al. Clinical characteristics and intrauterine vertical transmission potential of COVID-19 infection in nine pregnant women: a retrospective review of medical records. Lancet [Internet]. 2020; 395 (10226): 
809-815. Available in: http://dx.doi.org/10.1016/S0140-6736 (20)30360-3

25. Cascella M, Rajnik M, Cuomo A, Dulebohn SC, Di Napoli R. Features, evaluation and treatment coronavirus (COVID-19). StatPearls [Internet]. 2020; 1-17. Available in: http://www.ncbi. nlm.nih.gov/pubmed/32150360

26. Ferguson NM, Laydon D, Nedjati-Gilani G, Imai N, Ainslie K, Baguelin $\mathrm{M}$ et al. Impact of non-pharmaceutical interventions (NPIs) to reduce COVID-19 mortality and healthcare demand. London, UK: Imperial College London; 2020. Available in: https://doi.org/10.25561/77482

27. Rothe C, Schunk M, Sothmann P, Bretzel G, Froeschl G, Wallrauch $\mathrm{C}$ et al. Transmission of 2019-NCOV infection from an asymptomatic contact in Germany. N Engl J Med. 2020; 382 (10): 970-971.

28. van Doremalen N, Bushmaker T, Morris DH, Holbrook MG, Gamble A, Williamson BN et al. Aerosol and surface stability of SARS-CoV-2 as compared with SARS-CoV-1. N Engl J Med [Internet]. 2020; 382 (16): 1564-1567. Available in: https://doi. org/10.1056/NEJMc2004973

29. Li G, Fan Y, Lai Y, Han T, Li Z, Zhou P et al. Coronavirus infections and immune responses. J Med Virol. 2020; 92 (4): 424-432.

30. Imai Y, Kuba K, Rao S, Huan Y, Guo F, Guan B et al. Angiotensinconverting enzyme 2 protects from severe acute lung failure. Nature. 2005; 436 (7047): 112-116.

31. Hofmann H, Pyrc K, Van Der Hoek L, Geier M, Berkhout B, Pöhlmann S. Human coronavirus NL63 employs the severe acute respiratory syndrome coronavirus receptor for cellular entry. Proc Natl Acad Sci U S A. 2005; 102 (22): 7988-7993.

32. Guan WJ, Ni ZY, Hu Y, Liang WH, Ou CQ, He JX et al. Clinical characteristics of coronavirus disease 2019 in China. N Engl J Med [Internet]. 2020; 382 (18): 1708-1720. Available in: http:// www.ncbi.nlm.nih.gov/pubmed/32109013

33. Fang L, Karakiulakis G, Roth M. Are patients with hypertension and diabetes mellitus at increased risk for COVID-19 infection? Lancet Respir Med [Internet]. 2020; 8 (4): e21. Available in: http://dx.doi.org/10.1016/S2213-2600 (20)30116-8

34. Esler M, Esler D. Can angiotensin receptor-blocking drugs perhaps be harmful in the COVID-19 pandemic? J Hypertens [Internet]. 2020; 38: 1-2. Available in: https://journals.Iww.com/ jhypertension

35. Gurwitz D. Angiotensin receptor blockers as tentative SARSCoV-2 therapeutics. Drug Dev Res. 2020; 10.1002/ddr.21656. doi:10.1002/ddr.21656.

36. Vaduganathan M, Vardeny $\mathrm{O}$, Michel T, McMurray JJV, Pfeffer MA, Solomon SD. Renin-angiotensin-aldosterone system inhibitors in patients with COVID-19. N Engl J Med. 2020; 382 (17): 1653-1659. doi: 10.1056/NEJMsr2005760.

37. Khan A, Benthin C, Zeno B, Albertson TE, Boyd J, Christie JD et al. A pilot clinical trial of recombinant human angiotensinconverting enzyme 2 in acute respiratory distress syndrome. Crit Care. 2017; 21 (1): 234

38. Ishiyama Y, Gallagher PE, Averill DB, Tallant EA, Brosnihan KB, Ferrario CM. Upregulation of angiotensin-converting enzyme 2 after myocardial infarction by blockade of angiotensin II receptors. Hypertension. 2004; 43 (5): 970-976.

39. Jessup JA, Gallagher PE, Averill DB, Brosnihan KB, Tallant EA, Chappell MC et al. Effect of angiotensin II blockade on a new congenic model of hypertension derived from transgenic Ren-2 rats. Am J Physiol Hear Circ Physiol. 2006; 291 (5): 2166-2172.

40. Hamming I, Van Goor H, Turner AJ, Rushworth CA, Michaud $A A$, Corvol $P$ et al. Differential regulation of renal angiotensin- converting enzyme (ACE) and ACE2 during ACE inhibition and dietary sodium restriction in healthy rats. Exp Physiol. 2008; 93 (5): 631-638.

41. Furuhashi M, Moniwa N, Mita T, Fuseya T, Ishimura S, Ohno K et al. Urinary angiotensin-converting enzyme 2 in hypertensive patients may be increased by olmesartan, an angiotensin II receptor blocker. Am J Hypertens. 2015; 28 (1): 15-21.

42. Luque M, Martin P, Martell N, Fernandez C, Brosnihan KB, Ferrario CM. Effects of captopril related to increased levels of prostacyclin and angiotensin- (1-7) in essential hypertension. J Hypertens [Internet]. 1996; 14 (6): 799-805. Available in: https:// journals.Iww.com/jhypertension/Fulltext/1996/06000/Effects_ of_captopril_related_to_increased_levels.17.aspx

43. Bozkurt B, Kovacs R, Harrington B. Joint HFSA/ACC/ AHA Statement addresses concerns re: using RAAS antagonists in COVID-19. J Card Fail [Internet]. 2020; 26 (5): 370. Available in: https://www.acc.org/latest-in-cardiology/ articles/2020/03/17/08/59/hfsa-acc-aha-statement-addressesconcerns-re-using-raas-antagonists-in-covid-19

44. Su H, Yang M, Wan C, Yi LX, Tang F, Zhu HY et al. Renal histopathological analysis of 26 postmortem findings of patients with COVID-19 in China. Kidney Int. 2020. doi: 10.1016/j. kint.2020.04.003.

45. Li Q, Cheng Q, Zhao Z, Zeng L, Wei G, Li C et al. Two renal transplant recipients: case report. 2020.

46. Kissling S, Rotman S, Gerber C, Halfon M, Lamoth F, Comte $\mathrm{D}$ et al. Collapsing glomerulopathy in a COVID-19 patient. Kidney Int [Internet]. 2020. Available in: https://doi.org/10.1016/j. kint.2020.04.006

47. Channappanavar R, Perlman S. Pathogenic human coronavirus infections: causes and consequences of cytokine storm and immunopathology. Semin Immunopathol. 2017; 39 (5): 529-539.

48. Rokni M, Ghasemi V, Tavakoli Z. Immune responses and pathogenesis of SARS-CoV-2 during an outbreak in Iran: Comparison with SARS and MERS. Rev Med Virol. 2020; 30 (3): e2107.

49. Ahmadpoor $P$, Rostaing $L$. Why the immune system fails to mount an adaptive immune response to a COVID-19 infection. Transpl Int. 2020; 13-14.

50. Zhou G, Zhao Q. Perspectives on therapeutic neutralizing antibodies against the Novel Coronavirus SARS-CoV-2. Int J Biol Sci. 2020; 16 (10): 1718-1723.

51. Qin C, Zhou L, Hu Z, Zhang S, Yang S, Tao Y et al. Dysregulation of immune response in patients with COVID-19 in Wuhan, China. Clin Infect Dis. 2020. doi: 10.1093/cid/ciaa248.

52. Zhao J, Yuan Q, Wang H, Liu W, Liao X, Su Y et al. Antibody responses to SARS-CoV-2 in patients of novel coronavirus disease 2019. Clin Infect Dis. 2020. doi: 10.1093/cid/ ciaa344.

53. Wu LP, Wang NC, Chang YH, Tian XY, Na DY, Zhang LY et al. Duration of antibody responses after severe acute respiratory syndrome. Emerg Infect Dis. 2007; 13 (10): 1562-1564.

54. Liu W, Fontanet A, Zhang P, Zhan L, Xin Z, Baril L et al. Twoyear prospective study of the humoral immune response of patients with severe acute respiratory syndrome. J Infect Dis. 2006; 193 (6): 792-795.

55. Liu L, Wei Q, Lin Q, Fang J, Wang $\mathrm{H}$, Kwok $\mathrm{H}$ et al. Anti-spike IgG causes severe acute lung injury by skewing macrophage responses during acute SARS-CoV infection. JCI Insight. 2019; 4 (4): e123158.

56. Peiris JSM, Chu CM, Cheng VCC, Chan KS, Hung IFN, Poon LLM et al. Clinical progression and viral load in a community 
outbreak of coronavirus-associated SARS pneumonia: a prospective study. Lancet. 2003; 361 (9371): 1767-172.

57. Zhang L, Zhang F, Yu W, He T, Yu J, Yi CE et al. Antibody responses against SARS coronavirus are correlated with disease outcome of infected individuals. J Med Virol [Internet]. 2006; 78 (1): 1-8. Available in: https://doi.org/10.1002/ jmv.20499

58. Fu Y, Cheng Y, Wu Y. Understanding SARS-CoV-2-mediated inflammatory responses: from mechanisms to potential therapeutic tools. Virol Sin [Internet]. 2020. Available in: https:// doi.org/10.1007/s12250-020-00207-4

Correspondencia:

Dr. Luis Eduardo Morales-Buenrostro Vasco de Quiroga Núm. 15,

Col. Belisario Domínguez, Sección XVI, Tlalpan, 14080, Ciudad de México, México.

E-mail: luis_buenrostro@yahoo.com 